\title{
Out of Sync Subnational Housing Markets and Macroprudential Policies in the UK
}

\section{Michael Funke ${ }^{1,2} \cdot$ Petar Mihaylovski $^{3} \cdot$ Adrian Wende $^{1}$ (D)}

Accepted: 6 September 2021 / Published online: 9 October 2021

(c) The Author(s) 2021

\begin{abstract}
We examine whether regionally differentiated macroprudential policies can address financial stability concerns and moderate house price differences in the UK. We disaggregate both the household sector and the housing stock in a two-region DSGE model with out of sync subnational housing markets and compare four policy types: standard monetary policy, leaning against the wind monetary policy, national macroprudential policy or one that targets region-specific LTV ratios. In terms of reducing variances of house prices, regionally differentiated macroprudential policy performs best, provided the policy authorities are concerned with stabilising output and house prices rather than simply minimising the variance of inflation.
\end{abstract}

Keywords Macroprudential Policies · Housing · DSGE · Great Britain

JEL Classificatoin E32 $\cdot$ E44 $\cdot$ E52 $\cdot$ E58

The paper has benefitted from seminar participants at the Bank of Finland, Reserve Bank of New Zealand, Estonian Eesti Pank, Hong Kong University, the University of Tübingen, the University of Leipzig, and the University of Hamburg. We would like to thank the editor and an anonymous referee for helpful comments and suggestions on an earlier draft. The usual disclaimer applies.

Adrian Wende

adrian.wende@uni-hamburg.de

Michael Funke

michael.funke@uni-hamburg.de; michael.funke@taltech.ee

Petar Mihaylovski

pmihaylovski@gmail.com

1 Department of Economics, Hamburg University, Hamburg, Germany

2 Department of Economics and Finance, Tallinn University of Technology, Tallinn, Estonia

3 Finance in Motion GmbH, Frankfurt, Germany 


\section{Introduction}

In the aftermath of the global financial crisis, macroeconomic research has argued that house price movements are the source of-rather than the consequence ofbusiness cycle fluctuations. ${ }^{1}$ The fact that property is bought with large amounts of debt is one reason why housing market outcomes over the past ten years have been so volatile. In an upswing, when expectations are that house prices will continue to rise, the returns from using debt to finance house acquisitions look very high and homeowners even can use their larger housing equity to finance additional consumption expenditures with mortgage debt. However, all those forces go into reverse once the expectation that house prices will rise evaporates and the perceived probability that house prices might fall substantially becomes significant.

The macroprudential housing policy toolkit is meant to mitigate such boom-bust patterns in financial markets. ${ }^{2}$ A problem that has emerged is that housing markets are geographically disconnected. ${ }^{3}$ How should the macroprudential policy be designed if national house price indices mask large variation at the regional and metropolitan area level? Are region-specific macroprudential measures better suited than a national macroprudential policy design to reduce or remove the risks stemming from out of sync house price movements? ${ }^{4}$

A look at regional UK house prices in the left panel of Fig. 1 reveals the lack of synchronicity and is indicative of three clusters of regions. The first clustergloom-consists of five regions (Northeast, Northwest, Yorkshire, East Midlands, West Midlands) in which house prices fell substantially during the global financial crisis and have remained on the low level. The second-bust and boom-consists of three regions (East, Southeast, Southwest) in which housing markets have rebounded since 2009 after falling sharply during 2008-2009. The third cluster-boom-comprises London, in which the pronounced drop in house prices in 2008-2009 was followed by a quick rebound and a significant rise. In addition, the right panel of Fig. 1 depicts the average regional house prices relative to house prices in London. The relative house prices illustrate Great Britain's different house price dynamics.

Against the background of these regional differences in house price dynamics, we develop a prototype multi-regional DSGE model to analyse exuberant house price dynamics in subnational areas in the face of national versus region-specific macroprudential measures. Disaggregating not only the household sector but also the housing stock in a two-region DSGE model with out of sync subnational housing

\footnotetext{
${ }^{1}$ Leamer (2015) has even argued that housing is the business cycle.

2 A growing literature has documented the use of macroprudential housing policies across countries and analysed their effects. Galati and Moessner (2013), Galati and Moessner (2018) and Lubis et al. (2019) have provided reviews of the macroprudential housing-finance toolkit and give an overview of what is known about the effects of macroprudential policies.

3 See, for example, Van Nieuwerburgh and Weill (2010) and Hernández-Murillo et al. (2017) for analyses of the level and dispersion of house prices across US metropolitan areas.

4 In many macroprudential studies, the uneven house price dynamics is mostly discussed as an afterthought. A notable exception is the Bruegel policy contribution by Claeys et al. (2017), who propose regionally differentiated macroprudential policies.
} 

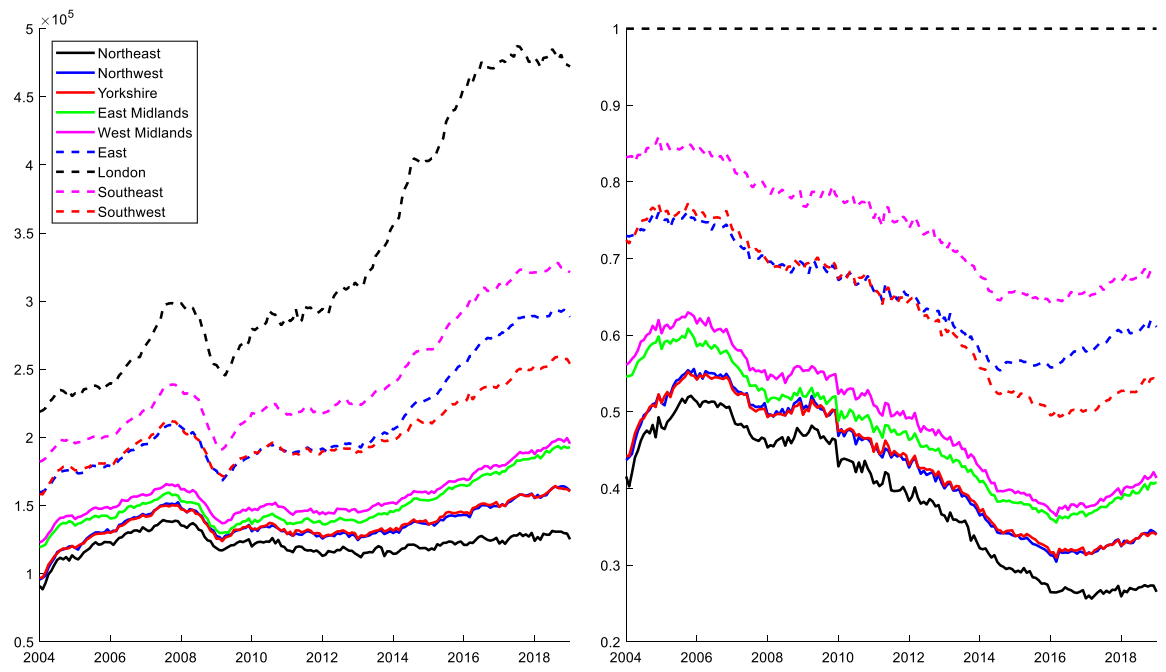

Fig. 1 Average nominal house prices by English Region, January 2004-January 2019. Source: UK Office for National Statistics, own calculations

markets will provide valuable insights into the transmission of region-specific fundamental and/or policy shocks across localised metropolitan regions. ${ }^{5}$ Great Britain's regional house price differences may ultimately indicate that there is no one-sizefits-all-national macroprudential policy. Instead region-specific macroprudential policies might be advisable. While modelling macroprudential policy at the national level is reaching a mature stage, the assessment of macroprudential policies at the subnational level in a DSGE framework is still a fertile area for research. In particular, we shall investigate whether a country-wide monetary policy and region-specific macroprudential policies can be a helpful combination, favouring macroeconomic performance and financial stability at both the regional and country-wide level.

The roadmap to the reminder of the paper is as follows. Section 2 describes the DSGE modelling framework. Section 3 puts forward the calibration, while Sect. 4 presents the resulting impulse responses and Sect. 5 discusses efficient policy frontiers. Finally, Sect. 6 summarises and discusses policy implications.

\section{The Model Setup}

Isolating the effect of macro-prudential policies and their impact, from complementary policies and/or other economic developments, constitutes a significant challenge and requires cautious interpretations. To address this difficulty, a large strand

\footnotetext{
${ }^{5}$ Despite a different research question, the DSGE model employed in this paper is related to the recent open economy DSGE literature analysing monetary policy in heterogeous monetary unions. See, for example, Brzoza-Brzezina et al. (2015), Rubio and Carrasco-Gallego (2016) and Rubio (2018).
} 
of the literature employs DSGE frameworks. ${ }^{6}$ Precisely in this tradition, this section models the macroprudential toolkit in the UK in a two-region open-economy DSGE framework. $^{7}$

In what follows, we describe in detail the maximisation problems and the respective first-order conditions of the first region; however, those of the second region are analogous. Both regions share mostly the same structural parameter calibration but face region-specific shocks. The weight of the household living in the first region is $\lambda \in[0,1]$, the weight of the borrowers $\omega \in[0,1]$ is equal for both regions, and all variables of the household in the second region are indicated by an asterisk. Furthermore, we interpret and calibrate the first region to match London and the second region to the rest of the UK (thereinafter abbreviated by "L" and "R", respectively). In other words: there are two types of households in each region. ${ }^{8}$

\subsection{Households}

Two types of households, borrowers and savers, living in London maximise

$$
E_{0} \sum_{t=0}^{\infty} \beta_{i}^{t}\left[\frac{1}{1-\sigma}\left(X_{t}^{i}\right)^{1-\sigma}-\frac{v_{i}}{1+\varphi}\left(N_{t}^{i}\right)^{1+\varphi}\right],
$$

where $i \in\{b, s\}$ indicates the household type, $X_{t}^{i}$ is the consumption bundle, $N_{j, t}^{i}$ represents an aggregate labour index, $\varphi$ and $\sigma$ are the corresponding intertemporal elasticities of substitution with respect to labour and consumption, $v_{i}$ allows for differences in the weighting of utility losses from labour, depending on the household type, and is calibrated in a way that in the steady state it holds $N^{s} \approx N^{b} \approx 1 / 3 . \beta_{i}$ represents the household's discount factor. The savers are assumed to be more patient compared to the borrowers, that is $\beta_{s}>\beta_{b}$. Following Funke and Paetz (2013), as well as Monacelli (2009), the consumption index is a weighted average of the flow of non-housing consumption expenditures and the stock of housing,

\footnotetext{
${ }^{6}$ The DSGE modelling approach is based on the assumptions of rational expectations, intertemporal optimization, and market clearing and hence is coherent. Moreover, DSGE models typically feature a unique deterministic steady state. The steady state is determinate and intrinsically stable. This paper follows this modelling tradition. Conversely, this means that the paper does not consider bubbles. In bubble models, multiple equilibria and indeterminate steady states may exist. Sunspot equilibria can arise, and economic fluctuations can be driven by sunspot shocks, which are unrelated to economic fundamentals. In some cases, multiple steady states can exist. Some of them are stable and others are not. Even in the absence of any shocks, a deterministic equilibrium system may exhibit chaotic dynamics or periodic orbits. For an attempt to establish bridges between these disparate strands of literature, see Miao et al. (2015).

${ }^{7}$ The descriptive evidence in Fig. 1 suggests the existence of three house price clusters. No further conclusions can be drawn from a three-region modelling framework in comparison with a two-region framework. For the sake of brevity we therefore limit ourselves to a two-region DSGE model.

${ }^{8}$ In the interest of a space-saving model presentation, individual model components have been moved to the Online Appendix.
} 


$$
X_{t}^{i}=C_{t}^{i\left(1-\gamma \varepsilon_{\gamma, t}\right)} D_{t}^{i \gamma \varepsilon_{\gamma, t}},
$$

where $C_{t}^{i}$ and $D_{t}^{i}$ represent composite indices of non-housing and housing consumption, respectively, $\gamma$ is the share of housing in utility determining the relative size of the non-durable versus the durable sector and $\varepsilon_{\gamma, t}=\exp \left(e_{\gamma, t}\right)$ is a housing preference shock that affects the marginal rate of substitution between non-housing and housing goods. Housing consumption is given by the standard CES aggregator.

$$
D_{t}^{i} \equiv\left[(1-\alpha)^{\frac{1}{\eta}} D_{L, t}^{i \frac{\eta-1}{\eta}}+\alpha^{\frac{1}{\eta}} D_{R, t}^{i \frac{\eta-1}{\eta}}\right]^{\frac{\eta}{\eta-1}} .
$$

Thus, each household derives utility from consuming both housing in the home region of London, $D_{L, t}^{i}$, and housing in the rest of the UK, $D_{R, t}^{i}$, but with a home bias equal to $(1-\alpha)$. The inverse home bias parameter $\alpha$ has a different calibration in London than in the rest of the UK; that is, in exception to all structural parameters, there exists also an $\alpha^{*}$. Through this model assumption, we consider the possibility of commuting, which in principle allows households to evade housing price increases. The assessment of commuting patterns across the European Union (EU) reveals that London is the EU region with the highest number of within-country commuters. Almost half $(48.6 \%)$ of the workforce commutes to work from/to another UK region. ${ }^{9}$ The parameter $\eta$ stands for the intratemporal elasticity of substitution between housing in London and housing in the rest of the UK.

Like in Horvath (2000), the aggregate labour index is given by

$$
N_{t}^{i}=\left[N_{C, t}^{i \frac{1+\zeta}{\zeta}}+N_{D L, t}^{i \frac{1+\zeta}{\zeta}}\right]^{\frac{\zeta}{1+\zeta}},
$$

where $N_{j, t}^{i}$ is labour supplied in sector $j$. Overall, there are three production sectors, indicated by $j \in\{C, D L, D R\}$, that are the consumption sector common to both regions, the housing production sector in London and the housing production sector in the rest of the UK. But the households in London can only supply labour in the common consumption and the housing production sector in London. $\zeta$ determines the elasticity of labour supply across the two sectors. If $\zeta=\infty$, hours worked in both sectors are perfect substitutes from the perspective of the household.

\subsubsection{Savers}

The patient household's budget constraint is given by

\footnotetext{
${ }^{9}$ For a detailed analysis at the NUTS2-Level, see https://ec.europa.eu/eurostat/statistics-explained/pdfsc ache/50943.pdf.
} 


$$
\begin{aligned}
C_{t}^{s} & +Q_{L, t} H_{L t}^{s}+Q_{R, t} H_{R t}^{s}+B_{t}^{s}+F_{t}=\Re_{t-1} \frac{B_{t-1}^{s}}{\pi_{C, t}}+\Re_{t-1} \frac{F_{t-1}}{\pi_{C, t}}+Q_{\mathcal{L}, t} \mathcal{L} \\
& +\sum_{j=C, D L} \frac{W_{j, t} N_{j, t}^{s}}{P_{C, t}}+\sum_{j=C, D L} \frac{Z_{j, t}}{P_{C, t}}+T_{t}^{s},
\end{aligned}
$$

where $\pi_{C, t+1}=\frac{P_{C, t+1}}{P_{C, t}}$ is the inflation rate of the non-durable consumption good, $Q_{L, t}$ and $Q_{R, t}$ are real housing prices in London and in the rest of the $\mathrm{UK}$, respectively, $B_{t}^{s}$ represents the stock of real domestic debt (both denominated with the domestic nonhousing price index), $\mathfrak{R}_{t}$ the nominal interest rate and $Q_{\mathcal{L}, t}$ is the real price that a firm has to pay to the household for the fixed factor land $\mathcal{L}$. $W_{j, t}$ denotes the sectorspecific nominal wage rate, $H_{L, t}^{s}=D_{L, t}^{s}-(1-\delta) D_{L, t-1}^{s}$ defines housing investment in London, whereas $\delta$ represents the depreciation rate of the housing stock. $H_{R t}^{s}$ is the similarly defined housing investment in the rest of the UK. Furthermore, we assume savers to have access to complete international asset markets, whereby $F_{t}$ denotes the nominal payoff in period $t+1$ of state contingent claims (excluding the oneperiod bond) purchased in period $t$. In addition, $Z_{j, t}$ stands for the profits earned by savers for owning intermediate good firms and $T_{t}^{S}$ indicates government lump-sum taxes paid by savers.

\subsubsection{Borrowers}

The utility maximisation of the impatient household is subject to the budget constraint

$$
C_{t}^{b}+Q_{L, t} H_{L, t}^{b}+Q_{R, t} H_{R, t}^{b}+\Re_{t-1} \frac{B_{t-1}^{b}}{\pi_{C, t}}=B_{t}^{b}+\sum_{j=C, D L} \frac{W_{j, t} N_{j, t}^{b}}{P_{C, t}}+T_{t}^{b},
$$

where similar to the savers' case, $H_{t}^{b}$ is the flow of new housing demanded by borrowers, $N_{j, t}^{b}$ stands for the labour supply provided by borrowers at the prevailing market wage rate in both the consumption and housing industry and $T_{t}^{b}$ denotes lumpsum taxes paid by borrowers. In addition, the latter optimally choose the level of real domestic debt, denoted by $B_{t}^{b}$, and pay the nominal interest rate $R_{t-1}$ for the amount of credit borrowed in the previous period. It is worth mentioning that borrowers in both regions have access to credit provided by both savers and not just the saver in their respective region. That implies in equilibrium $B_{t}^{b}+B_{t}^{b *}+B_{t}^{s}+B_{t}^{s *}=0$. A salient feature of the modelling framework is the borrowing constraint, in the spirit of Kiyotaki and Moore (1997), which borrowers face each period:

$$
\Re_{t} B_{t}^{b} \leq \kappa_{t}(1-\delta) E_{t}\left[\left(Q_{L, t+1} D_{L, t}^{b}+Q_{R, t+1} D_{R, t}^{b}\right) \pi_{C, t+1}\right] \varepsilon_{c r, t}
$$

Equation (7) relates the amount that will be repaid by a borrower in the following period, relative to the expected future value of the housing stock (adjusted for depreciation). Thus, the borrower's debt can be interpreted as mortgage contracts. $\kappa_{t}$ represents the time-varying LTV ratio, which is a policy variable. The LTV constraint 
is binding in and around the steady state. Moreover, we introduce a credit shock called $\varepsilon_{c r, t}=\exp \left(e_{c r, t}\right)$ in the sense of Favara and Imbs (2015).

Recent literature emphasises the role of fixed and adjustable-rate mortgage contracts for monetary and macroprudential policy transmission. We assume all mortgage contracts to be adjustable, because, in the UK, the predominant mortgage contract is an adjustable-rate mortgage. We define $\tau_{t}^{b}$ and $\tau_{t}^{b} \psi_{t}$ as the Lagrangian multipliers on the constraints, Eqs. (6) and (7), with the result that the first-order conditions of the respective optimisation problem become:

$$
\begin{gathered}
\tau_{t}^{b}=\left(1-\gamma \varepsilon_{\gamma, t}\right) X_{t}^{b-\sigma}\left(\frac{D_{t}^{b}}{C_{t}^{b}}\right)^{\gamma \varepsilon_{\gamma, t}} \\
\frac{W_{j, t}}{P_{C, t}}=\frac{\nu_{s}\left(N_{t}^{b}\right)^{\varphi} \frac{\partial N_{t}^{b}}{\partial N_{j, t}^{b}}}{\tau_{t}^{b}} \\
Q_{L, t} \tau_{t}^{b}=\frac{\gamma \varepsilon_{\gamma, t}}{1-\gamma \varepsilon_{\gamma, t}} \frac{C_{t}^{b}}{D_{t}^{b}} \tau_{t}^{b} \frac{\partial D_{t}^{b}}{\partial D_{L, t}^{b}}+\beta_{b}(1-\delta) E_{t}\left\{Q_{L, t+1} \tau_{t+1}^{b}\right\}+\psi_{t} \kappa_{t} \varepsilon_{c r, t}(1-\delta) E_{t} Q_{L, t+1} \tau_{t}^{b} \pi_{C, t+1} \\
Q_{R, t} \tau_{t}^{b}=\frac{\gamma \varepsilon_{\gamma, t}}{1-\gamma \varepsilon_{\gamma, t}} \frac{C_{t}^{b}}{D_{t}^{b}} \tau_{t}^{b} \frac{\partial D_{t}^{b}}{\partial D_{R, t}^{b}}+\beta_{b}(1-\delta) E_{t}\left\{Q_{R, t+1} \tau_{t+1}^{b}\right\}+\psi_{t} \kappa_{t} \varepsilon_{c r, t}(1-\delta) E_{t} Q_{R, t+1} \tau_{t}^{b} \pi_{C, t+1} \\
\psi_{t} \Re_{t}=1-\beta_{b} E_{t}\left\{\frac{\tau_{t+1}^{b}}{\tau_{t}^{b}} \frac{\mathfrak{R}_{t}}{\pi_{t+1}}\right\}
\end{gathered}
$$

Equation (8) equates the Lagrangian multiplier, $\tau_{t}^{b}$, with the marginal value of non-durable consumption, Eq. (9) is the labour supply condition, equalising the real wage to the marginal rate of substitution between consumption and leisure, Eqs. (10) and (11) set the marginal value of housing in terms of non-durable consumption equal to its payoff and Eq. (12) is the Euler equation for one-period bond holdings. If $\psi_{t}=0$, the first-order conditions of the borrower would essentially reduce to the saver's first-order conditions. $\psi_{t}$ can be interpreted as the marginal value of borrowing. With $\psi_{t}$ being positive, from Eq. (12) follows $\tau_{t}^{b}>\beta_{b} \mathfrak{R}_{t} E_{t}\left\{\tau_{t+1}^{b} / \pi_{t+1}\right\}$, or in words, the borrower's present is larger than his future marginal value of non-durable consumption. This again implies that the borrower would be willing to plunge deeper into debt to increase current consumption if he could. Therefore, and as one can see in Eqs. (10) and (11), the borrower gets additional utility from owning houses, because he can use these as collateral (for further discussion of $\psi_{t}$ see Monacelli, 2009). 


\subsection{Firms}

We model the consumption goods sector as common to both regions. Thus, consumers face only one price of the non-durable consumption good independent of their location or their type.In contrast, the production of housing is region-specific. The structure of the production sector is as follows: monopolistically competitive firms produce either (exclusively) intermediate consumption goods or residential structures. Pricing of these firms is the familiar Calvo case. In the consumption sector, they sell these intermediate goods to firms producing final consumption goods; whereas in the housing production sector, they sell it to firms producing final residential structures. Out of these final residential structures, combined with land, another firm then constructs final houses. The consumption sector is standard in the New Keynesian literature, the housing production sector is similar to Davis and Heathcote (2005).

The assumption of region-specific housing construction firms allows us to account for differences in land and regulatory restrictions in London and the rest of the UK. The reason these differences are important lies in the fact that the UK has a particularly strict planning regime. There is significant discretion allocated to local planners when dealing with applications and granting permissions to build. A special feature is the Green Belt land. Land designated to be within the Green Belt is intended to prevent urban sprawl, and is largely protected from development. ${ }^{10}$

Here, we only present the problem of the housing construction firms in London, but the firms in the rest of the UK face a similar maximisation problem. The housing construction firms maximise their profit in a perfect competitive environment. To construct new houses, they combine land and final residential structures through the Cobb-Douglas production function

$$
Y_{H L, t}=Y_{D L, t}^{1-\vartheta_{L}} \mathcal{L}_{L}^{\vartheta_{L}}
$$

$Y_{H L, t}$ denotes new houses produced, $Y_{D L, t}$ is residential structures produced by final goods firms, $\mathcal{L}_{L}$ is land bought from patient households and $\vartheta_{L}$ is a parameter that weights the importance of land and labour in the production of new housing. Similar to Davis and Heathcote (2005), we assume a constant amount of new land being available for residential development in each period. ${ }^{11}$ But unlike previous literature, the newly available land, $\mathcal{L}_{L}$ and $\mathcal{L}_{R}$, as well as the weighting parameters, $\vartheta_{L}$ and $\vartheta_{R}$, are region-specific. Differences in $\mathcal{L}_{L}$ and $\mathcal{L}_{R}$ lead to price disparities of housing in the steady state. The housing construction firm maximises its profit by solving the static problem

\footnotetext{
10 According to Hilber and Vermeulen (2016), house prices in the South East would have been about $25 \%$ lower in 2008 if this region had the same regulatory restrictiveness as the North East.

11 The fixity of newly available developed land arises from the time horizon of the model. Our focus is not on the long run. On the contrary, any long-run framework has to model how endogenous shifts in the cost of land relative to structures changes the way in which houses are constructed. One paper in this spirit is Deaton and Laroque (2001).
} 


$$
\operatorname{MaxP}_{L, t} Y_{H L, t}-P_{D L, t} Y_{D L, t}-P_{\mathcal{L}, t} \mathcal{L}
$$

where $P_{L, t}$ is the nominal market price for housing in London, $P_{D L, t}$ is the nominal price for final residential structures and $P_{\mathcal{L}}$ is the nominal price the firm has to pay to the household for using land. The resulting housing price in London can be represented in real terms by

$$
Q_{L, t}=\left(1-\vartheta_{L}\right)^{-\left(1-\vartheta_{L}\right)} \vartheta_{L}^{-\vartheta_{L}} Q_{D L, t}^{1-\vartheta_{L}} Q_{\mathcal{L}, t}^{\vartheta_{L}}
$$

Final residential structures as well as non-durable consumption goods are produced by monopolistically competitive producers of intermediates that are subject to Calvo pricing and perfectly competetive final good firms. As a result, the following New Keynesian Phillips curve expressions can be obtained:

$$
\begin{gathered}
\hat{\pi}_{C, t}=\beta_{s} E_{t} \hat{\pi}_{C, t+1}+\frac{\left(1-\theta_{C}\right)\left(1-\theta_{C} \beta_{s}\right)}{\theta_{C}} \widehat{M C}_{C, t}+e_{\pi_{C}, t} \\
\hat{\pi}_{D L, t}=\beta_{s} E_{t} \hat{\pi}_{D L, t+1}+\frac{\left(1-\theta_{D}\right)\left(1-\theta_{D} \beta_{s}\right)}{\theta_{D}} \widehat{M C}_{D L, t}+e_{\pi_{D L}, t} \\
\hat{\pi}_{D R, t}=\beta_{s} E_{t} \hat{\pi}_{D R, t+1}^{*}+\frac{\left(1-\theta_{D}\right)\left(1-\theta_{D} \beta_{s}\right)}{\theta_{D}} \widehat{M C}_{D R, t}+e_{\pi_{D R}, t}
\end{gathered}
$$

where $\theta_{C}$ and $\theta_{D}$ are the probabilities a price remains sticky in the respective sector. The stochastic processes $e_{\pi_{C}, t}, e_{\pi_{D L}, t}$ and $e_{\pi_{D R}, t}$ can be interpreted as cost push shocks.

\subsection{Market Clearing and Foreign Demand}

Aggregate market clearing in the housing market in London requires that the supply of housing goods is equal to demand in each period:

$$
Y_{H L, t}=\lambda\left[D_{L, t}-(1-\delta) D_{L, t-1}\right]+(1-\lambda)\left[D_{L, t}^{*}-(1-\delta) D_{L, t-1}^{*}\right]+e^{F}
$$

$e^{F}$ denotes a foreign demand shock. The influence of foreign demand is evident in the frothiness of London's property market, where the eagerness of foreign nationals drives a wedge between house prices and local fundamentals. They are willing to pay above the odds to secure a safe haven for their savings. ${ }^{12}$ The demand shock is assumed to only affect London. Thus, the housing market clearing in the rest of the UK is given by

\footnotetext{
12 Badarinza and Ramadorai (2018) found that increased political risk worldwide explained 8 percent of the variation in London's house prices since 1998.
} 


$$
Y_{H R, t}=\lambda\left[D_{R, t}-(1-\delta) D_{R, t-1}\right]+(1-\lambda)\left[D_{R, t}^{*}-(1-\delta) D_{R, t-1}^{*}\right]
$$

The stock of housing in London owned by Londoners is given by $D_{L, t}=\omega D_{L, t}^{b}+(1-\omega) D_{L, t^{\circ}}^{s}$. The housing stock in the rest of the UK owned by households from London, $D_{R, t}$, the housing stock in the rest of the UK owned by households from the rest of the UK, $D_{R, t}^{*}$, and the housing stock in London owned by households from the rest of the UK, $D_{L, t}^{*}$, are defined the same way. Moreover, aggregate output of non-durable consumption goods has to equal aggregate consumption, $Y_{C, t}=C_{t}^{T}$, where aggregate consumption is given by $C_{t}^{T}=\lambda C_{t}+(1-\lambda) C_{t}^{*}$, with $C_{t}=\omega C_{t}^{b}+(1-\omega) C_{t}^{s}$ and $C_{t}^{*}$ analogous. Aggregate labour supply of borrowers and savers in London is given by $N_{t}^{b}=N_{C, t}^{b}+N_{D L, t}^{b}$ and $N_{t}^{s}=N_{C, t}^{s}+N_{D L, t}^{s}$, respectively. Moreover, aggregate labour supply in the intermediate goods sectors is given by $N_{D L, t}=\omega N_{D L, t}^{b}+(1-\omega) N_{D L, t}^{s}$ for housing in London and, because there is only one consumption good sector for both regions, by $N_{C, t}=\lambda\left(\omega N_{C, t}^{b}+(1-\omega) N_{C, t}^{s}\right)+(1-\lambda)\left(\omega N_{C, t}^{b *}+(1-\omega) N_{C, t}^{s *}\right)$ for intermediate non-durable consumption goods. Labour market clearing requires $N_{j, t}=\int_{0}^{1} N_{j, t}(z) d z$. For every definition or market clearing equation that is only presented for London there exist a similar equation for the rest of the UK.

\subsection{Monetary and Macroprudential Policy}

We analyse four different combinations of monetary and national and regional macroprudential policy. Monetary policy is always modelled by means of a traditional Taylor rule. Following the literature (Funke \& Paetz, 2018; Lambertini et al., 2013; Rubio, 2018) macroprudential policy via a Taylor-like LTV rule. We assume this LTV rule to react on house prices, that is, the higher the house prices, the lower the LTV ratio and vice versa. ${ }^{13}$ We consider four alternative policy options.

\subsubsection{Policy Type 1: Monetary Policy Exclusively by Means of a Standard Taylor Rule}

As a reference case, we assume the loan-to-value (LTV) ratio, $\kappa_{t}$, to be fixed and monetary policy to be conducted by the Taylor rule

$$
\frac{\mathfrak{R}_{t}}{\mathfrak{R}}=\left(\frac{\mathfrak{R}_{t-1}}{\mathfrak{R}}\right)^{\rho_{r}}\left[\pi_{C P I, t}^{\phi_{\pi}}\left(\tilde{Y}_{t}\right)^{\phi_{y}}\right]^{1-\rho_{r}} \varepsilon_{t}^{m} .
$$

where $\varepsilon_{t}^{m}=\exp \left(e_{t}^{m}\right)$ stands for a monetary policy shock, $\rho_{r} \in[0,1]$ determines the interest-rate inertia, $\phi_{\pi}$ and $\phi_{\alpha}$ are parameters associated with the sensitivity of interest rates to current inflation and the output gap, respectively. Similar to Monacelli

\footnotetext{
13 Instead the Bank of England has employed loan-to-income (LTI) limits. LTI flow limits can effectively constrain the proportion of high LTV lending since an individual borrower's LTI and LTV are mechanically linked through the house price to income ratio. In other words, limits on high LTI lending effectively constrain high LTV, too. See Bank of England (2017), p. 12.
} 
(2009), monetary policy reacts to a composite inflation index, comprising inflation of non-durable consumption goods and housing inflation, which is given by $\pi_{C P I, t}=\pi_{C, t}^{(1-\chi)}\left(\pi_{D L, t}^{\lambda} \pi_{D R, t}^{(1-\lambda)}\right)^{\chi}$. Moreover, we assume that monetary policy reacts to the output gap $\tilde{Y}_{t}=\frac{Y_{t}^{a}}{Y_{t}^{n}}$, where $Y_{t}^{n}$ is the output under flexible prices and $Y_{t}^{a}=Y_{c}+\frac{P_{D L}}{P_{C}} Y_{D}+\frac{P_{D R}}{P_{C}} Y_{D}^{*}$ is aggregate real output.

\subsubsection{Policy Type 2: Leaning Against the Wind Taylor Rule Policy}

Under this policy option, the Taylor rule reacts more strongly to aggregate house price inflation. This rule is given by

$$
\frac{\mathfrak{R}_{t}}{\mathfrak{R}}=\left(\frac{\mathfrak{R}_{t-1}}{\mathfrak{R}}\right)^{\rho_{r}}\left[\check{\pi}_{C P I, t}^{\phi_{\pi}}\left(\tilde{Y}_{t}\right)^{\phi_{y}}\right]^{1-\rho_{r}} \varepsilon_{t}^{m},
$$

where $\check{\pi}_{C P I, t}=\pi_{C, t}^{\left(1-\chi-\phi_{D}\right)}\left(\pi_{D L, t}^{\lambda} \pi_{D R, t}^{(1-\lambda)}\right)^{\left(\chi+\phi_{D}\right)}$ and $\phi_{D}$ measures the additional weight of aggregate house price inflation. Leaning against the wind policies are controversial. The most prominent opponent of leaning against the wind policies is Svensson (2014) arguing that the costs of such policies far outweigh any potential benefit. Other authors, in contrast, reach the opposite conclusion and argue that the gains from preventing a crisis are likely to exceed the costs of a slowdown (see, e.g., Gambacorta \& Signoretti, 2014).

\subsubsection{Policy Type 3: Monetary Policy by Means of a Standard Taylor Rule and National Macroprudential Policy}

The focus upon macroprudential policies reflects the increasing scepticism towards standard monetary policy in tempering housing booms in support of financial stability. We introduce macroprudential policy in our model via the Taylor-like LTV rule.

$$
\kappa_{t}=\kappa_{t}^{*}=\kappa_{s s}\left(\frac{Q_{t}^{n}}{Q_{s s}^{n}}\right)^{-\xi},
$$

which reacts to deviations of the national real house price index $Q_{t}^{n}=\lambda Q_{L t}+(1-\lambda) Q_{t}^{*}$ from its steady state value $Q_{s s}^{n}$. The sensitivity of this reaction is determined by the parameter $\xi$ and $\kappa_{s s}$ is the steady state LTV ratio.

\subsubsection{Policy Type 4: Monetary Policy by Means of a Standard Taylor Rule and Regional Differentiated Macroprudential Policy}

The regional housing market divergence may call for regionally differentiated macroprudential policies. To examine this possibility, we introduce two region-specific LTV rules, which constitute the third policy regime. These LTV rules are given by 


$$
\kappa_{t}=\kappa_{s s}\left(\frac{Q_{L, t}}{Q_{L, s s}}\right)^{-\xi}
$$

and

$$
\kappa_{t}^{*}=\kappa_{s s}^{*}\left(\frac{Q_{R, t}}{Q_{R, s s}}\right)^{-\xi},
$$

respectively. In other words, the regional-specific LTV rules react to deviations of regional real house prices, $Q_{L, t}$ and $Q_{R, t}$, from their particular steady state. The 4 th policy approach can thus be referred to as an attempt to square the circle of monetary policy at the national level and macroprudential policy at the sub-national level.

Such a strategy of regional differentiated macroprudential policy has recently been applied in, for example, New Zealand, where restrictions on high-LTV lending were tightened specifically for the Auckland housing market (Reserve Bank of New Zealand, 2015). Korea has put in place a differentiated application of LTV ratios according to zip-codes. As explained in detail by Igan and Kang (2011), limits are set differently for so-called speculative and non-speculative zones. Moreover, in response to the sustained run-up in house prices, the Chinese authorities have introduced city-level macroprudential policies targeting cities where the price dynamics have been most pronounced (see Funke et al., 2019). But also in Europe regional macroprudential policy is put into practice already. Norway requires its mortagage lenders to have a maximum LTV ratio of $85 \%$ but only $60 \%$ for homes in Oslo. Denmark has debt-to-income regulations that only apply for areas with significant price increases, currently the cities Copenhagen and Aarhus (for more details see European Systemic Risk Board, 2018).

\subsection{Stochastic Processes}

We analyse how our model economy reacts to certain shocks $v_{l, t}$. Here we give a short summary of the underlying stochastic processes, which are given by

$$
\begin{gathered}
a_{C, t}=\rho_{a_{C}} a_{C, t-1}+v_{a_{C}, t}, \\
a_{D, t}=\rho_{a_{D}} a_{D, t-1}+v_{a_{D}, t}, \\
e_{\gamma, t}=\rho_{\gamma} e_{\gamma, t-1}+v_{\gamma, t}, e_{\gamma^{*}, t}=\rho_{\gamma^{*}} e_{\gamma^{*}, t-1}+v_{\gamma^{*}, t}, \\
e_{c r, t}=\rho_{c r} e_{c r, t-1}+v_{c r, t}, e_{c r^{*}, t}=\rho_{c r^{*}} e_{c r^{*}, t-1}+v_{c r^{*}, t}, \\
e_{\pi_{C}, t}=v_{\pi_{C}, t}, e_{\pi_{D L}, t}=v_{\pi_{D L}, t}, e_{\pi_{D R}, t}=v_{\pi_{D R}, t}, \\
e_{m, t}=v_{m, t},
\end{gathered}
$$




$$
e_{F, t}=\rho_{F} e_{F, t-1}+v_{F, t},
$$

where all $v_{l, t} \sim N\left(0, \sigma_{l}^{2}\right)$ with the exception of $v_{\gamma, t}$ and $v_{\gamma^{*}, t}$. Labour productivity in the non-durable consumption goods sector evolves according to Eq. (26), the labour productivity in the housing goods sectors evolves according to Eq. (27). Region-specific housing preference shocks are defined by (28) as exogenous shocks to the marginal rate of substitution between non-durable consumption and housing. It seems reasonable to assume the preference shock process in London to be correlated to the respective process in the rest of the UK. Therefore, the preference shocks consist of a common and a region specific part according to

$$
\begin{gathered}
v_{\gamma, t}=v_{c o, t}+v_{r s, t} \\
v_{\gamma^{*}, t}=v_{c o, t}+v_{r s^{*}, t},
\end{gathered}
$$

where $v_{r s, t}$ and $v_{r s^{*}, t}$ are the region-specific preference shocks and $v_{c o, t}$ is the common preference shock. Equations (29), (30) and (31) denote the credit shocks, cost push shocks and the monetary policy shocks, respectively. Equation (32) is the process for the foreign demand shock.

In the following sections we shall map out the policy implications of the modelling framework. We first discuss the model calibration, then illustrate the model dynamics using impulse response and welfare analysis.

\section{Calibration}

Our goal is to calibrate the model with UK data and use it to explore the mechanism and efficiency of subnational macroprudential policies. Most parameters are chosen from estimates in the literature. Here, we restrict our discussion to parameters that determine steady state house prices, policy parameters and the calibration of shock processes that are important for matching the actual house price behaviour and the efficient policy frontiers in Sect. 5. For all other parameters and more information about the steady state with house price disparity, we refer the reader to the online Appendix.

In our model, steady state house price dispersion between London and the rest of the UK is mostly driven by the supply side, but also the parameters for home bias, $\alpha$ and $\alpha^{*}$, play some role. The latter were not estimated until now. Since most people prefer to live near to their workplace, the home bias should be quite large and we allow it to be different in the two regions. That is, we set the inverse home bias of London, $\alpha$, to $0.1(1-\lambda)$ and $\alpha^{*}$ takes on the value of $0.01 \lambda$. It is useful to think of the inverse home bias in terms of $\lambda$, since in the case of complete openness $\alpha$ would equal $(1-\lambda)$ and $\alpha^{*}$ would equal $\lambda$. Our parameter choice regarding land in the production function is directed towards matching the ratio of steady state house prices, $Q_{L} / Q_{R}$, incorporating slower housing supply adjustment in London compared to the rest of the UK. To achieve a reasonable steady state price ratio, we set land, which is a fixed factor of production, to 0.005 in London and 0.1 in the rest of the UK. 
Table 1 Important steady state ratios and SD implied by the calibration. Sources: UK Department for Communities and Local Government, Office of National Statistics and OECD

\begin{tabular}{llll}
\hline & Ratio & Actual & Model \\
\hline (1) & Non-durable Consumption to GDP in \% & 65.67 & 64.77 \\
$(2)$ & Gross fixed real estate capital formation to GDP in \% & 5.26 & 5.23 \\
$(3)$ & $(2) /(1)$ & 8.01 & 8.08 \\
$(4)$ & Newly built Dwellings in London to total newly built dwell- & 12.27 & 14.33 \\
& $\quad$ ings in the UK & 30 & 30 \\
$(5)$ & $\left(\mathrm{I}_{\mathrm{k}}+\mathrm{G}+\mathrm{NX}\right)$ to GDP & $1.5-2.4$ & 1.76 \\
$(6)$ & $Q_{L} / Q_{R}$ & & \\
\hline & SD & 5.83 & 6.62 \\
\hline (7) & House Prices in the UK & 11.02 & 11.06 \\
$(8)$ & House Prices in London & 5.91 & 5.76 \\
$(9)$ & House Prices in the rest of the UK & 1.86 & 1.92 \\
$(10)$ & (8)/(9) & 0.48 & 0.47 \\
$(11)$ & Correlation of $Q_{L}$ and $Q_{R}^{4}$ &
\end{tabular}

Hence, we obtain a steady state house price ratio of 1.76 . As regards the housing supply adjustment, it is of primary importance to properly pin down $\vartheta$ and $\vartheta^{*}$, which denote the weighting of land. We set the weight for the rest of the UK to 0.1, in line with Iacoviello and Neri (2010), and 0.2 in London in order to obtain a lower short-term supply elasticity. Furthermore, we choose the share of housing consumption in the utility function, $\gamma$, such that our model approximately matches the ratio of non-durable consumption to GDP of 66 percent (see Table 1). The specification of the LTV limits is based on information from the Bank of England. According to the Bank of England (2017), approximately 20 percent of new mortgage lending at origination had an LTV ratio larger than 90 percent in 2015, and above 80 percent of stock of mortgages had an LTV ratio lower than 75 percent. Thus, we set $\kappa_{s s}=\kappa_{s s}^{*}=0.75$.

Regarding the parameters entering the Taylor rule, we follow Harrison and Oomen (2010), and set $\rho_{r}=0.87, \phi_{\pi}=1.87$ and $\phi_{Y}=0.11$. The parameter determining the responsiveness of macroprudential policy to house price deviations $\xi$ amounts to 0.75 , and the additional weight on house price inflation in the lean against the wind policy, $\phi_{D}$, is assumed to be 0.3 .

Crucial to creating a trade-off in the model between the variance of inflation and the variance of output are the cost push shocks. For the UK, their standard deviation is estimated by Liu and Mumtaz (2011), in the range of 0.34 to 1.66 percent. We set the respecting variances to 1.2 percent. The variance of house prices in our model is to a large extent driven by housing preference shocks. We set the standard deviation of the common shock to 2 percent and the standard deviations of the regional shocks to 4.5 percent in London and to 1.5 percent in the rest of the UK. This implies standard deviations of the overall demand shocks, $v_{\gamma, t}$ and $v_{\gamma^{*}, t}$, of 4.9 and 2.5 percent, respectively. With this specification, our model is able to match actual standard deviations 

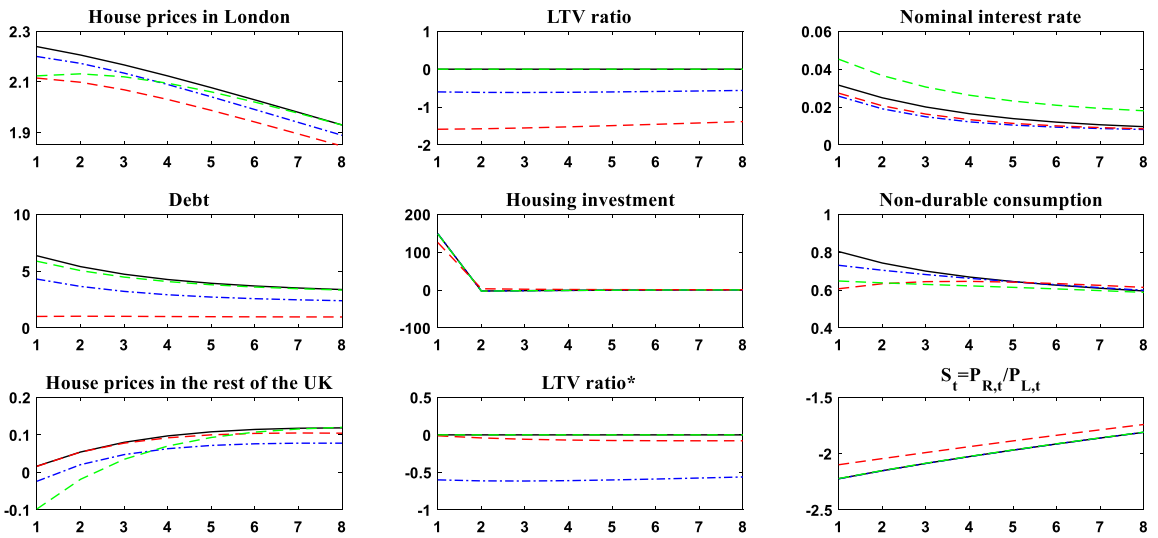

$S_{t}=P_{R, t} / P_{L, t}$
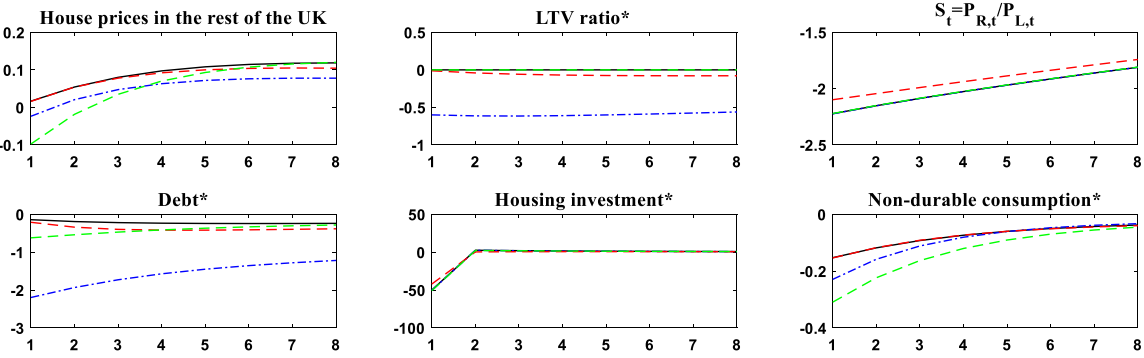

Inflation of non-durable consumption goods 0.05
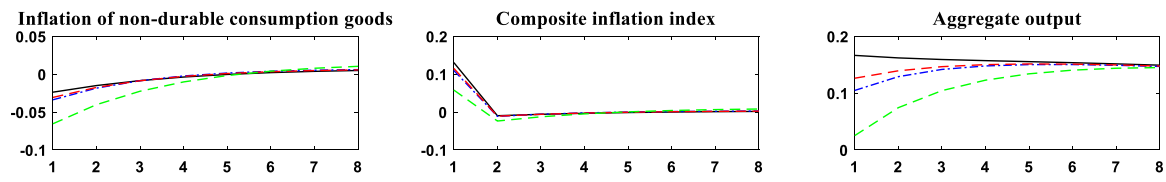

- Fixed LTV policy -----National LTV Policy - - - Regional LTV Policy - - - Lean against the wind Taylor Rule

Fig. 2 Impulse responses to a one-standard-deviation region specific housing preference shock in London (percentage deviations from the steady state)

and correlations of house prices quite well (see Table 1). Finally, we set the persistence of the credit shock process, $\rho_{c r}$, to 0.9 and the standard deviations of the credit shocks, $\sigma_{c r}$ and $\sigma_{c r}$, to 2 percent. All remaining standard deviations are obtained from Iacoviello and Neri (2010). Table 1 gives an overview of the ability of the model to match actual ratios, standard deviations and the correlation of house prices.

To solve the model we perform a first-order approximation around its non-stochastic steady state and use the software DYNARE to obtain impulse responses. In the next section we provide impulse responses to shed light upon the propagation of selected shocks and identifies the variables acting as main conduits in the propagation process.

\section{Impulse Response Analysis}

To illustrate the dynamic properties of the model, we focus on the impact of a regions-specific housing preference shock and a foreign demand shock. ${ }^{14}$ For each shock we consider the four policy scenarios. As before, the asterisk indicates variables in the rest of the UK.

\footnotetext{
14 See the online Appendix for the impulse responses of the credit shock and the technology shock in the housing industry. Both do not alter the conclusions of our paper.
} 
As a start, Fig. 2 shows the impulse responses to a one standard deviation housing preference shock affecting households in London. In general, i.e. with a fixed LTV ratio, a housing preference shock works as follows in our model. As demand for housing increases, house prices also increase. This directly affects the collateral constraint. The potential higher leverage and the wealth effect allow households to consume more durable and nondurable consumer goods. Thus, the increase in house prices leads to an increase in aggregate demand, which in turn leads to an increase in output. The increase in output generates inflation and monetary policy responds by raising interest rates. This in turn dampens the rise in house prices, which in the case of our model is particularly evident in the leaning against the wind policy, where the interest rate reacts more strongly. For more details on the mechanisms just described, see, for example, Iacoviello (2005) and Rubio and Carrasco-Gallego (2014).

So what happens under the different policy scenarios? As expected, the shock increases house prices in both regions and, thus, policymakers decrease the LTV ratios except for the policy scenario when the latter remains fixed. In the case of regional LTV policy, London house prices and, consequently, London LTV ratios exhibit a stronger response. In contrast, LTV ratios in the rest of the UK behave in the opposite manner and fall accordingly.

In all four policy cases, borrowers in London respond to higher house prices incurring more debt, whereby this excessive borrowing can only be prevented by means of LTV policy. National LTV policy leads to an overreaction of the LTV constraint in rest of the UK, forcing borrowers there to immediately sell bonds. An important aspect is that the regional LTV policy dampens house price increases in London most; however, the overall effect still remains small. National LTV policy even leads to somewhat higher housing prices in London, since it tends to reduce national inflation. This, in turn, induces the central bank to lower the nominal interest rate.

The strong increase in the housing investment of the London household is particularly striking. Housing investment is defined in our model as the change in the housing stock of the corresponding household (after depreciation). In the steady state, housing investment corresponds exactly to housing depreciation, according to our calibration 1 percent of the housing stock. An increase in housing investment by 130 percent therefore means an increase in the housing stock of the corresponding household by 1.3 percent, which in our Fig. 2 is roughly accompanied by an increase in house prices in London by 2.2 percent. It should also be borne in mind that households in our model can not only invest in new housing, but can also purchase property outside London from households in the rest of the UK (or purchase property in London from households in the rest of the UK). Thus, an increase in a household's housing stock is not the same as an increase in the construction of new dwellings. Moreover, we refrain from the ad hoc assumption of investment adjustment costs, thus large parts of the investments take place all at once.

Furthermore, it is worth scrutinising the leaning against the wind Taylor rule in more detail. Due to the additional weight on housing, the nominal interest rate exhibits a stronger increase compared to all other scenarios. This suppresses CPI inflation, and the latter drops below steady state for around five quarters, which, 

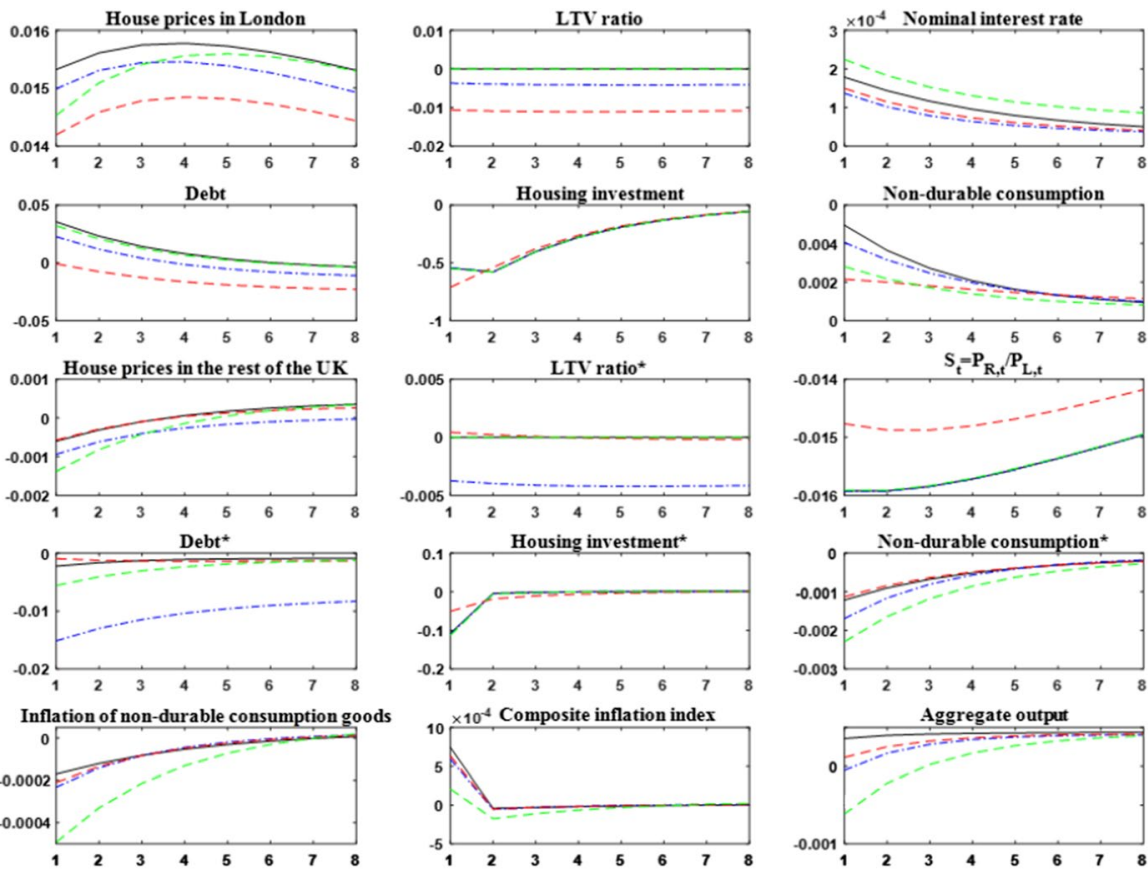

Fixed LTV policy -----National LTV Policy - - Regional LTV Policy

Lean against the wind Taylor Rule

Fig. 3 Impulse responses to a foreign demand shock in London (percentage deviations from the steady state)

in turn, leads to a rise in the real interest rate. Borrowers in both regions are induced to curb their debt levels (and housing demand) relative to the baseline scenario. Particularly evident is this effect in the rest of the UK. This induces borrowers in the rest of the UK to reduce their purchases of non-durable goods, which, in turn, reduces aggregate output relative to the baseline case. In London, however, the small interest rate increase in the case of the modified Taylor rule is not sufficiently strong as to induce substantial debt reductions. As regards house prices in London, introducing a modified leaning against the wind Taylor rule induces a small house price decline. In the rest of the UK, house prices fall slightly on impact relative to the benchmark scenario, but quickly increase due to the rise in demand from borrowers living in the capital region.

Overall, comparing all four policy scenarios and the impulse responses after a positive housing preference shock in London, it is unequivocally clear that regional macroprudential policies along with standard national monetary policy turns out to be most effective for stabilising debt and CPI inflation. If the monetary authority sets a single monetary and macroprudential policy for the entire country, this one size fits all policy is too tight (loose) in the $1^{\text {st }}$ region, and too loose (tight) in the 2 nd 
region, relative to a policy set optimally for each region. Monetary policy that reacts strongly to house prices without macroprudential assistance is not only subject to the one size fits all policy problem. In addition, it is rather ineffective in dampening the debt in the respecting region after a positive housing preference shock and results in deflationary pressure. ${ }^{15}$

Figure 3 shows the impulse responses to a foreign demand shock in London. House prices in London rise and macroprudential policy responds with a lower LTV ratio to dampen the excessive borrowing of the impatient households. Due to higher house price inflation, the central bank intervenes, albeit to a lesser extent in the case of macroprudential policy being in place. Households in London are induced to consume more non-durables, whereas the inhabitants of the in the rest of the UK curb their purchases of non-durable goods. The modified Taylor rule is quite ineffective in reducing the debt of the households and leads to a deflationary pressure regarding both house prices in the rest of the UK and prices of consumption goods.

The reaction of the housing market in the rest of the UK looks surprising at first sight. It appears that households in London do not play a large role in the housing market in the rest of the UK. One reason is that London is comparatively small. Beyond that, two further mechanisms are at work. Lower consumption leads to a larger marginal value of consumption, which leads to lower marginal cost and more production and employment in the housing industry. Thus, house prices in the rest of the UK fall, which reduces borrowers' debt. This effect is described by Monacelli (2009) in the context of a monetary policy shock. Notice that, for the rest of the UK, a sudden increase in demand for housing in London coming from abroad acts similarly to a monetary policy shock. The central bank increases the interest rate due to the rise of the composite inflation index. And while regional LTV policy can significantly moderate these effects, national LTV policy makes it even worse for the borrower in the rest of the UK.

\section{Policy Frontiers}

The policymaker in our modelling framework faces a trade-off between minimising the variances of inflation, output and house prices. A parsimonious way to characterise this trade-off and make normative policy statements feasible is to compute efficient frontiers. We compute these efficient frontiers, also called Taylor curves, in a fashion similar to Levin et al. (1999) and Rubio and Carrasco-Gallego (2014). It is important to bear in mind that the policymaker in our modelling framework not only considers the trade-off between inflation and output, but also consider house price variance as an additional target variable.

\footnotetext{
${ }^{15}$ In other words, the modelling framework supports the Tinbergen principle saying that one has to employ different tools for different objectives.
} 

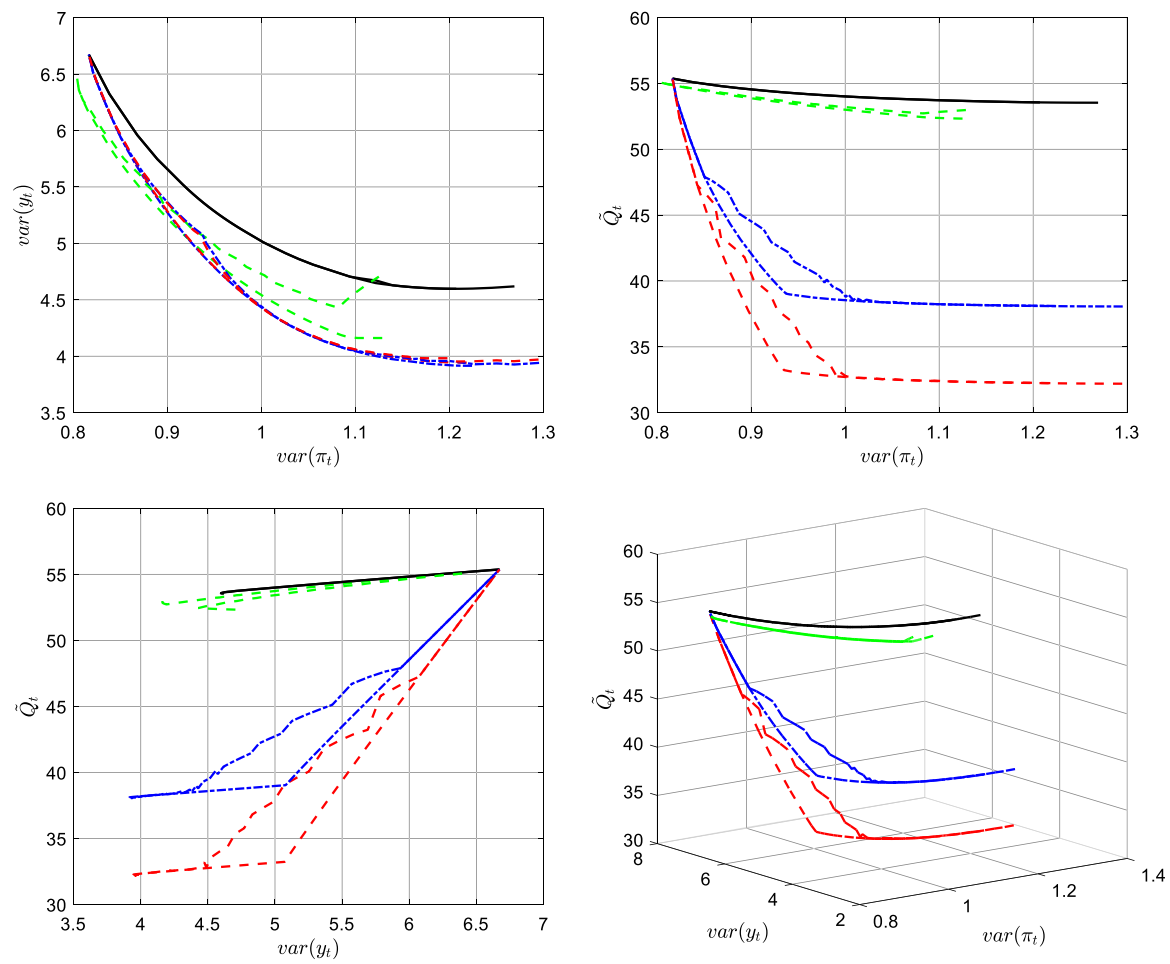

— Fixed LTV policy - - - Lean against the wind Taylor Rule ----- National LTV Policy - - - Regional LTV Policy

Fig. 4 Efficient policy frontiers

As a first step, we define a new target variable which is equal to the weighted average of both house price variances, that is $\tilde{Q}_{t}=\lambda \operatorname{var}\left(Q_{L, t}\right)+(1-\lambda) \operatorname{var}\left(Q_{R, t}\right) .{ }^{16}$ The procedure for computing the efficient policy frontiers is as follows. First, we compute the variances of the target variables with all possible combinations of the policy reaction parameters $\phi_{y}$ and $\xi$, ranging from 0 to 5, or, in the case of $\phi_{\pi}$ and $\phi_{D}$, from 1.1 to 5 and from 0 to 0.6 , respectively, for all four policy types. Similar to Iacoviello (2005), we discard all possible combinations which yield a variance of the interest rate larger than 25 percent above the benchmark calibration. Then, we solve the optimisation problem to obtain the efficient frontiers. Figure 4 depicts the results.

The top left figure depicts the outcomes in the inflation-output variance region, which is essentially the classical Taylor curve representation. To the right, the trade-off between the house price variance target variable and the variance of CPI inflation is shown. On the bottom left are efficient combinations of the house

\footnotetext{
16 Alternatively, it might seem natural to use the variance of the national house price index, $\operatorname{var}\left(Q_{t}^{n}\right)$ as target variable. The drawback of this approach is that policy might lower the correlation between both house prices indices. This could decrease the variance of $Q_{t}^{n}$ while holding constant or even increasing the variances of the regional house prices and thus we use $\tilde{Q}_{t}$ instead of $\operatorname{var}\left(Q_{t}^{n}\right)$.
} 
price target variable and the variance of output. For the latter two, it is particularly noticeable that two lines are shown for the LTV policies and for the lean against the wind policy. The reason for this is that in three-dimensional space the efficient frontier is a two-dimensional surface instead of a curve. The two lines mark the lateral boundaries of the surface and thus the associated policy options. An overall assessment is provided by the three-dimensional Taylor curve with all target variables of interest.

We can see that the policy variants $2-4$ are superior in terms of inflation and output variances. The national and regional LTV policies perform comparatively similarly. As expected, the leaning against the wind policy performs slightly better, if minimization of inflation is the primary goal. When using macroeconomic LTV policy, there is a trade-off between the variance of house prices and the vairance of CPI inflation, as can be seen in the top left panel. Thus, a policy maker who is only interested in CPI inflation would not pursue LTV policy. The top right panel illustrates that only region-specific LTV policies are able to reduce the house price variances by a substantial amount. This holds especially true for larger values of the parameter $\xi$. For $\xi=0.75$, for example, the house price variance in London declines by 7.8 percent in the case of a regional LTV policy and approximately 4.7 percent when a national LTV policy is carried out. This is more than what the leaning against the wind Taylor rule can achieve, even with large values for $\phi_{D}$.

A final question to be addressed is the mechanisms that drive these results. The classic trade-off between the variance of inflation and output is triggered by cost push shocks, as is well known in the literature. When cost push shocks increase inflation, the only way for the central bank to reduce inflation is to curb demand and thus output. Also, the trade-off between minimizing house price variances and inflation is caused by cost-push shocks, namely those in the non-durable consumer goods sector. When prices for these consumer goods rise through cost push shocks, inflation rises and real house prices fall. Attempts to stabilize the latter through lower interest rates or higher LTV ratios further fuel demand and hence inflation. In contrast, there is no trade-off between the variance of output and house prices. As described above, higher house prices (e.g. due to a housing preference shock) lead to higher debt, which in turn leads to higher aggregate demand and thus to higher output. Fluctuating house prices hence lead to fluctuating output. LTV policy breaks this chain of effects by reducing or even preventing the increase in debt.

In sum, the numerical results imply that a nation-wide monetary policy and a region-specific macroprudential policies is the preferred policy mix.

\section{Conclusion}

Financial stability is a necessity for economic growth. When the financial crisis burst out, it deeply reduced the trust in financial markets. The mix of macroprudential reforms undertaken since then has aimed at making financial institutions and the housing market safer. Beyond that, understanding, diagnosing and reversing the rapid increase in house prices is critical for the cohesiveness of UK society. High house prices are one of the factors causing one of the great divides in society today: 
that is, between the haves and the have-nots; between the older property-owning generation and younger renters who have difficulty getting on to the property ladder.

The presented modelling framework provides an intriguing view of the dynamics and effects of out of sync subnational house prices and macroprudential policies. Based on a DSGE model that emphasises out of sync house prices, we study the effects of national vs. subnational macroprudential policies. The impulse-response functions convey an unambiguous message. At the business cycle frequency, stabilising house prices by means of targeting the region-specific LTV ratio proves to be the most effective tool, especially if the shocks originate on the demand side of the economy and are region-specific. We furthermore construct Taylor curves which enable us to make some normative statements regarding which type of policy is "better" in terms of minimising the variation of inflation, output and house prices. Curves that lie closer to the origin represent a more efficient outcome and are thus preferred. The efficient policy frontiers clearly indicate that the most efficient tradeoffs, in terms of fulfilling our minimum variance criteria, are achieved when the macroprudential authority targets the region-specific LTV ratios. In short one can say that regionally differentiated LTV policies should be enacted to slow down hot spots while not slowing down cold spots.

Supplementary Information The online version contains supplementary material available at https://doi. org/10.1007/s10645-021-09394-1.

Funding Open Access funding enabled and organized by Projekt DEAL.

Open Access This article is licensed under a Creative Commons Attribution 4.0 International License, which permits use, sharing, adaptation, distribution and reproduction in any medium or format, as long as you give appropriate credit to the original author(s) and the source, provide a link to the Creative Commons licence, and indicate if changes were made. The images or other third party material in this article are included in the article's Creative Commons licence, unless indicated otherwise in a credit line to the material. If material is not included in the article's Creative Commons licence and your intended use is not permitted by statutory regulation or exceeds the permitted use, you will need to obtain permission directly from the copyright holder. To view a copy of this licence, visit http://creativecommons.org/licen ses/by/4.0/.

\section{References}

Badarinza, C., \& Ramadorai, T. (2018). Home away from home? Foreign demand and London house prices. Journal of Financial Economics, 130, 532-555.

Bank of England (2017). Financial Stability Report, June 2017, London.

Brzoza-Brzezina, M., Kolasa, M., \& Makarski, K. (2015). Macroprudential policy and imbalances in the Euro area. Journal of International Money and Finance, 51, 137-154.

Claeys, G., Efstathiou, K., \& D. Schoenmaker (2017). Spotting excessive regional house price growth and what to do about it. Bruegel Policy Contribution No. 26, Brussels.

Davis, M. A., \& Heathcote, J. (2005). Housing and the business cycle. International Economic Review, $46,751-784$.

Deaton, A., \& Laroque, G. (2001). Housing, land prices, and growth. Journal of Economic Growth, 6, 87-105.

European Systemic Risk Board. (2018). A Review of Macroprudential Policy in the EU in 2017. 
Favara, G., \& Imbs, J. (2015). Credit supply and the price of housing. American Economic Review, 105, 958-992.

Funke, M., \& Paetz, M. (2013). "Housing prices and the business cycle: An empirical application to Hong Kong. Journal of Housing Economics, 22, 62-76.

Funke, M., \& Paetz, M. (2018). A dynamic stochastic general equilibrium-based assessment of nonlinear macroprudential policies: Evidence from Hong Kong. Pacific Economic Review, 23, 632-657.

Funke, M., Tsang, A., \& Leiva-Leon, D. (2019). Mapping China's time-varying house price landscape. Regional Science and Urban Economics, 78, 1-16.

Galati, G., \& Moessner, R. (2013). Macroprudential policy: A literature review. Journal of Economic Surveys, 27, 846-878.

Galati, G., \& Moessner, R. (2018). What do we know about the effects of macroprudentail policy? Economica, 85, 735-770.

Gambacorta, L., \& Signoretti, F. M. (2014). Should monetary policy lean against the wind? An analysis based on a DSGE model with banking. Journal of Economic Dynamics and Control, 43, 146-174.

Harrison, R., \& Oomen, Ö. (2010). Evaluating and estimating a DSGE model for the United Kingdom. Bank of England Working Paper No. 380, London.

Hernández-Murillo, R., Owyang, M. T., \& Rubio, M. (2017). Clustered housing cycles. Regional Science \& Urban Economics, 66, 185-197.

Hilber, C. A. L., \& Vermeulen, W. (2016). The impact of supply constraints on house prices in England. Economic Journal, 126, 358-405.

Horvath, M. (2000). Sectoral shocks and aggregate fluctuations. Journal of Monetary Economics, 45, 69-106.

Iacoviello, M. (2005). House prices, borrowing constraints and monetary policy in the business cycle. The American Economic Review, 95, 739-764.

Iacoviello, M., \& Neri, S. (2010). Housing market spillovers: Evidence from an estimated DSGE model. American Economic Journal: Macroeconomics, 2, 125-164.

Igan, D. \& Kang, H. (2011). Do Loan-to-Value and Debt-to-Income Limits Work? Evidence from Korea, IMF Working Paper No. 11/297, Washington.

Lambertini, L., Mendicino, C., \& Punzi, M. (2013). Leaning Against Boom-Bust Cycles in Credit and Housing Prices. Journal of Economic Dynamics and Control, 37, 1500-1522.

Leamer, E. E. (2015). Housing Really is the Business Cycle: What Survives the Lessons of 2008-09? Journal of Money, Credit and Banking, 47, 43-50.

Levin, A., Wieland, V., \& Williams, J. C. (1999). Robustness of simple monetary policy rules under model uncertainty. In J. B. Taylor (Ed.), Monetary Policy Rules (pp. 263-318). Chicago: University of Chicago Press.

Liu, P., \& Mumtaz, H. (2011). Evolving Macroeconomic Dynamics in a Small Open Economy: An Estimated Markov Switching DSGE Model for the UK. Journal of Money, Credit and Banking, 43, 1443-1474.

Lubis, A., Alexiou, C., \& Nellis, J. G. (2019). What Can We Learn From the Implementation of Monetary and Macroprudential Policies: A Systematic Literature Review. Journal of Economic Surveys, $33,1123-1150$.

Miao, J., Wang, P., \& Xu, Z. (2015). A Bayesian DSGE Model of Stock Market Bubbles and Business Cycles. Quantitative Economics, 6, 599-635.

Monacelli, T. (2009). New Keynesian Models, Durable Goods, and Collateral Constraints. Journal of Monetary Economics, 56, 242-254.

Moore, J., \& Kiyotaki, N. (1997). Credit Cycles. Journal of Political Economy, 105, 211-248.

Reserve Bank of New Zealand (2015) Financial Stability Report, May 2015. Wellington.

Rubio, M. (2018). National Macroprudential Policies in the Euro Area: Flexibility vs. Supervision. Economics Letters, 170, 55-58.

Rubio, M., \& Carrasco-Gallego, J. A. (2014). Macroprudential and Monetary Policies: Implications for Financial Stability and Welfare. Journal of Banking and Finance, 49, 326-336.

Rubio, M., \& Carrasco-Gallego, J. A. (2016). Coordinating Macroprudential Policies within the Euro Area: The Case of Spain. Economic Modelling, 59, 570-582.

Svensson, L. E. O. (2014). Inflation Targeting and 'leaning against the wind.' International Journal of Central Banking, 10, 103-114. 
Van Nieuwerburgh, S., \& Weill, P. O. (2010). Why Has House Price Dispersion Gone Up? Review of Economic Studies, 77, 1567-1606.

Publisher's Note Springer Nature remains neutral with regard to jurisdictional claims in published maps and institutional affiliations. 